\title{
PHTHALATES RELEASED AFTER ERYTHROCYTE SUSPENSION: DO THEY POSE A RISK?
}

\author{
Edip Gonullu ${ }^{1}$, Sevdegul Bilvanisi ${ }^{1}$, Aydın Tasdogen ${ }^{1}$, Hayriye Gonullu ${ }^{1}$, Yüksel Erkin ${ }^{1}$, \\ Tuncay Kume ${ }^{2}$, and Mehmet Coşkun Aykaç ${ }^{1}$ \\ ${ }^{1}$ Affiliation not available \\ ${ }^{2}$ Dokuz Eylul University
}

February 17, 2021

\begin{abstract}
It is commonly known that stored blood and blood products are heated before transfusion in order to prevent hypothermia, which leads to increased di-(2-ethylhexyl) phthalate content leaching into the blood and blood products and thereby causes greater conversion of di-(2-ethylhexyl) phthalate to mono (2-ethylhexyl) phthalate. However, there has been no study in the literature reporting on the amount of toxic phthalates in blood following the erythrocyte suspension transfused via warming. In this study, we aimed to investigate the di-(2-ethylhexyl) phthalate and mono (2-ethylhexyl) phthalate content in blood following the ES transfusions administered by di-(2-ethylhexyl) phthalate -containing and di-(2-ethylhexyl) phthalate -free infusion sets. The study included 30 patients that were randomly divided into 2 groups with 15 patients each: group I underwent erythrocyte suspension transfusion via di-(2-ethylhexyl) phthalate -containing infusion sets warmed with blood-fluid warmers and group II underwent erythrocyte suspension transfusion via di-(2-ethylhexyl) phthalate-free infusion sets warmed with blood-fluid warmers. Di-(2-ethylhexyl) phthalate and mono (2-ethylhexyl) phthalate levels were measured both before and after transfusion. Di-(2-ethylhexyl) phthalate-free infusion sets led to no increase in the phthalate content, whereas di- $(2-$ ethylhexyl) phthalate-containing infusion sets significantly increased the di-(2-ethylhexyl) phthalate and mono (2-ethylhexyl) phthalate levels, where the di-(2-ethylhexyl) phthalate level increased almost four times $(\mathrm{p}=0.001)$. Di- $(2$-ethylhexyl) phthalatecontaining products lead to toxicity. Therefore, using di-(2-ethylhexyl) phthalate-free products may prevent toxicity in patients undergoing erythrocyte suspension transfusion.
\end{abstract}

\section{Hosted file}

Main document.pdf available at https://authorea.com/users/396341/articles/509562-phthalatesreleased-after-erythrocyte-suspension-do-they-pose-a-risk 

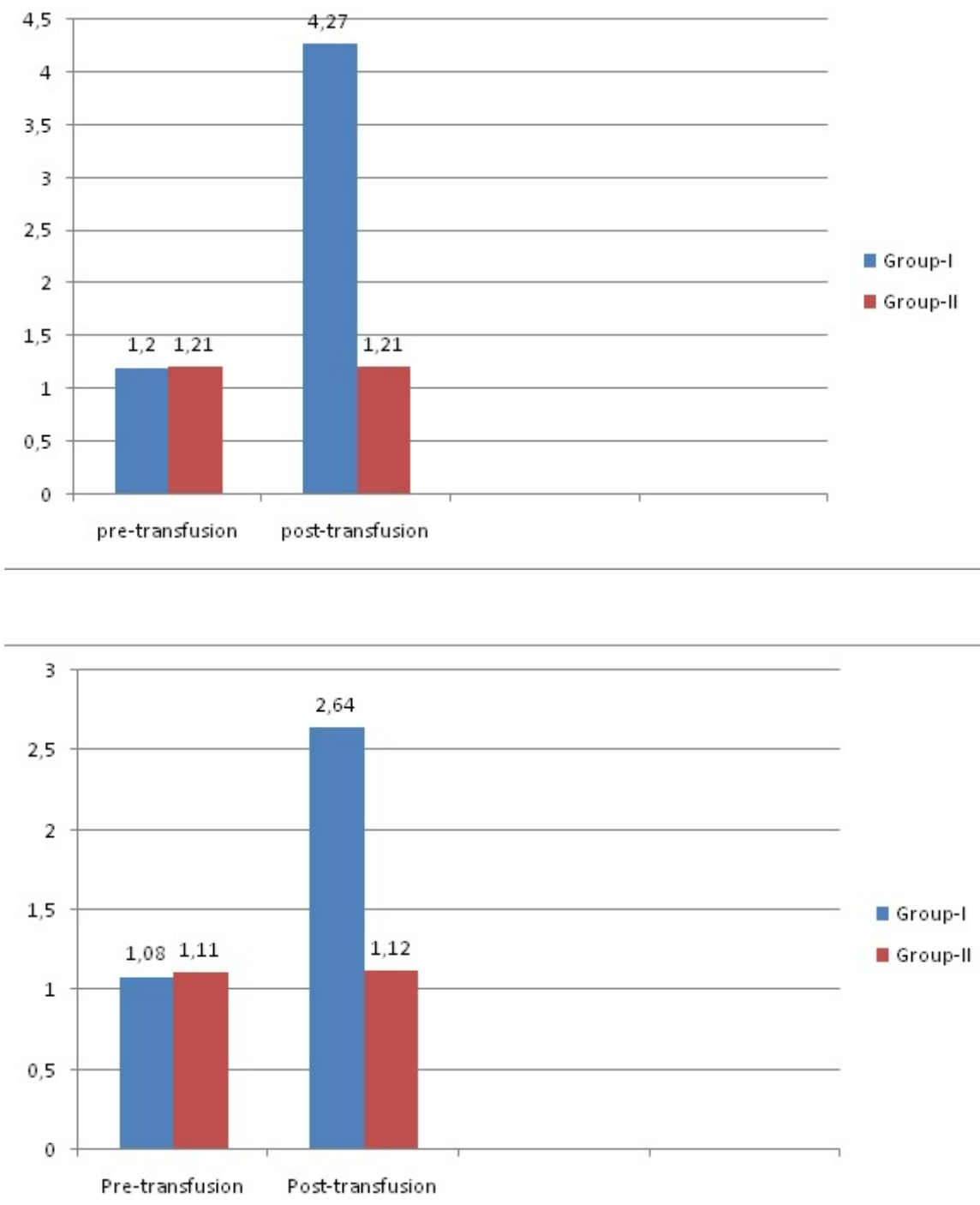